\section{Sexo Cerebral: Um Caminbo Que Começa a Ser Percorrido}

\section{RESUMO}

Fica cada vez mais claro que ocorre um dimorfismo sexual no cér ebro de homens e mulheres, e experi ências em animais têm mostrado que circuitos específicos se desenvol vem de acordo com o sexo do animal. Desde os trabalhos iniciais de Gorski em ratos, que descreviam o núcleo sexualm ente dimórfico n a áre a pré-óptica (SDN-POA), tem sido aceito que, por ação do estradiol, convertido localmente pela aromatase a partir de testoster ona, faz-s e o imprint para sexo masculi no, i nibindo-se a apoptose das célul as do SDN-POA e, portanto, levando a um núcleo anatomicamente maior e $m$ machos quando comparado ao de fêmeas. Outras regiões têm mostrado dimorfi smo sexual e necessi tamos de um marcador para que tais estrut uras sejam difer enciadas e possam ser avali adas na prática clínica. Este dado será de grande val ia na atribui ção de gênero a pacientes portadores de anomalias da diferenciação sexual, que nascem com ambigüidade genital. Têm havido muitas dúvi das na atribuição do gênero a alguns desses pacientes e não têm sido infreqüentes inadequações sexuais, com mudanças de opções sexuais em época puberal, com grandes traumas tanto para o paciente como para seus familiares. A evolução dos conhecimentos nessa ár ea poderá nos trazer elementos muito importantes para nos auxil iar na atri buição do sexo de criação em vários estados intersexuais e é um caminho que, apesar de estar ainda no seu iníci o, merece ser percorri do. (Arq Bras Endocrinol Metab 2005;49/1:37 45)

Descritores: Dimorfismo sexual; Genitália ambígua; Inters exo; Sexo cerebra I; Sexo social; Siste ma nervos o central

\begin{abstract}
Brain Sex: Just Beginning To Pave The Way.

It has become clear that a sexual brain dimorphism exists between males and females and animal studies have shown specific circuits developing depending on the sex. Since the first studies by Gor ski, in rats, characterizing a sexually dimor phic nucleus in the pre optic area (SDN-POA) it has been accepted that the male sex imprint is done by estradiol, locally converted from testosterone through the action of a local aromatase. The presence of estradiol inhibits the apoptosis of the cells of SDN, making it bigger in the male sex. Other CNS regions have shown sexual dimor phism and we need a marker to allow us to identify these structures and, eventually, apply this information to clinical practice. In intersex patients, it may be of value to know which the brain sex of the patient is, since we have had many doubts in choosing the sex of rearing in many of these patients. It has not been uncommon that sexual inadequacies have occurred in some patients, causing a lot of discomfort and suffering for the patient himself as well as to his family. The progr ession of the knowledge in the field of brain sex may bring us another tool to deal with difficult cases of sex assignment in intersex patients. (Arq Bras Endocrinol Metab 2005; 49/1:37-45)
\end{abstract}

Keywords: Ambiguous genitalia; Brain sex; Central nervous system; Intersex; Sexual dimorphism; Social sex atualização

\author{
Durval Damiani \\ Daniel Damiani \\ Taisa M. Ribeivo \\ Nuvarte Setian
}

Unidade de Endocrinologia

Pediátrica (DuD \& NS), Instituto da Criança, Hospital das Clinicas da Faculdade de Medicina da Universidade de São Paulo - USP; e Universidade de Santo Amaro - UNISA (DaD \& TMR), São Paulo, SP.
Recebido em 08/10/04 Aceito em 30/10/04 
$\mathbf{N}$ AS ÚlTiMAS DÉCADAS, muito se tem aprendido com relação aos mecanismos de determinação gonadal (entendida como a fase de desenvolvimento desde uma gônada indiferenciada, bipotencial, até um testículo ou um ovário) e de diferenciação sexual (os mecanismos a partir de uma gônada já definida que levam o indivíduo ao seu sexo final, masculino ou feminino). Particularmente, a partir da década de 80 , com $\mathrm{o}$ advento de técnicas de Biologia Molecular, muitos genes têm sido incorporados a uma verdadeira "cascata de determinação gonadal", receptores hormonais têm sido caracterizados, defeitos em hormônios, receptores e em ações pós-receptor têm sido descritos e nos ajudam a compreender as causas de muitos casos de anomalias da diferenciação sexual.

O campo de estudo das anomalias da diferenciação sexual sempre tem procurado subsídios nas exceções: desde uma proposta inicial em que a presença de um cromossomo $Y$ era necessária e suficiente para o desenvolvimento de um indivíduo para o sexo masculino e sua ausência justificava o desenvolvimento para o sexo feminino, casos que não se enquadravam no mo delo, tais como homem XX, mulher XY, hermafroditas verdadeiros $\mathrm{XX}$ obrigaram a procura de mecanismos mais finos para justificar tais ocorrências. Dessa forma, surgiu a fase do antígeno $\mathrm{HY}$ que, se presente em um indivíduo que não tivesse cromossomo $\mathrm{Y}$ justificava $\mathrm{O}$ desenvolvimento para sexo masculino. Logo, no entanto, verificou-se que estávamos com o "candidato errado" e, a partir dos primeiros trabalhos com técnicas de biologia molecular, surge o ZFY $(1,2)$ e, logo após, o SRY (Sex-determining Region of the $Y$ chromosome) (3), hoje o sinalizador reconhecido como TDF (Testis Determining Factor), localizado no braço curto do cromossomo Y. Muitos outros genes têm sido acrescentados a esse circuito e a lista cresce a cada dia (4).

Quando se analisa, na escala zoológica, a diferenciação sexual, vários aspectos são chamativos e trazem grandes questionamentos quando se procura compreender que mecanismo está por trás de uma determinada modificação. Apenas a título de exemplificação, interessante notar que em alguns peixes (sheepshead, um peixe da Califórnia), a diferenciação sexual segue um estímulo visual! Esses peixes vivem em cardumes de cerca de 20 fêmeas, comandadas por um macho, distinto das fềmeas fenotipicamente (cor, aspecto físico, tipos de nadadeiras, órgãos sexuais, gônadas). Quando este macho é retirado do cardume, uma fêmea, para manter o equilíbrio da espécie, em alguns dias sofre todas as transformações para sexo masculino e passa a comandar o cardume. Estes achados nos dizem claramente que há situações, na escala zoológica, em que não é o patrimônio genético ou o ambiente hormonal que comandam a diferenciação sexual, mas a necessidade de manutenção da espécie, percebida pela ausência do líder macho no grupo (5).

Do ponto de vista prático, a opção quanto ao sexo de criação tem se baseado no tamanho do falo e no posicionamento do meato uretral e não tem sido infreqüente a opção feminina em pseudo-hermafroditas masculinos, com cariótipo 46,XY e testículos. A evolução desses pacientes, que muitas vezes assumem o sexo psicológico masculino em época puberal, tem feito com que se reconsiderem os critérios de indicação do sexo de criação (6-9).

$\mathrm{Se}$, por um lado, evolui o conhecimento de mecanismos que levam uma gônada indiferenciada a testículo ou a ovário, bem como mecanismos envolvidos na construção de um fenótipo não ambíguo, por outro ficamos sem saber o que acontece no aspecto cognitivo, cerebral e a questão que fica é: há diferença entre o cérebro masculino e o feminino? Ou seja, o cérebro é um órgão sexualmente dimórfico? Não se tem avançado muito neste aspecto e isto é compreensível, dadas as dificuldades de exploração de uma estrutura da complexidade do cérebro, mas uma série de evidências têm se acumulado e tornam, hoje, imperioso o enfrentamento deste desafio que, a bem da verdade, tem sido feito há algumas décadas, como iniciativas isoladas. Há indicações de que tanto estruturas neurais e não neurais $\mathrm{XX}$ e $\mathrm{XY}$ diferenciam-se antes mesmo de serem influenciadas por hormônios (10).

Se a resposta à questão da diferença entre um cérebro masculino e feminino for afirmativa, como realmente parece ser, uma série de outras perguntas se seguem:

Por que e como diferem os sistemas nervosos de machos e fềmeas? ser reversível?

Em que fase ocorre tal diferenciação? Ela pode

Quem comanda a diferenciação cerebral? Hormônios? Fatores genéticos? Fatores ambientais?

Quais as implicações práticas do conhecimento do dimorfismo sexual cerebral?

Neste artigo, reunimos trabalhos que têm abordado o assunto e percebemos que este caminho, que começa a ser percorrido, pode nos trazer informações de grande valia, não somente no sentido acadêmico, mas também no campo da aplicabilidade clínica.

\section{Por que e como diferem os sistemas nervosos de machos e fêmeas?}

Há uma enorme complexidade quando estudamos os sistemas envolvidos no comportamento sexual dos 
animais, desde comportamentos expressivos para atração do parceiro até a amamentação de filhotes. Uma vez que o comportamento depende da estrutura e da função do sistema nervoso, podemos imaginar e elaborar teorias de que o sistema nervoso de machos e fêmeas não é igual, tanto na forma anatômica como também nas atividades fisiológicas. Isto fica ainda mais claro quando imaginamos que estruturas corporais exclusivas de machos ou fêmeas possuem mecanismos de regulação cerebral distintos, próprios de cada um dos sexos (11).

Nos cérebros humanos os dimorfismos são pequenos, sutis, difíceis de serem encontrados; núcleos hipotalâmicos variam em seus volumes médios quando comparamos homens e mulheres, mas as variações são tais que não conseguimos ainda determinar um perfil a ser seguido. Já nos roedores, pesquisadores conseguem dizer se o cérebro pertence a um macho ou a uma fềmea baseando-se apenas no volume hipotalâmico, com pequena probabilidade de erro. Em algumas espécies de aves canoras, apenas os machos cantam e, analisando seus cérebros, verificamos uma área para o canto muito mais desenvolvida do que em fềmeas (12). Para dificultar ainda mais nosso estudo, as variações nos comportamentos sexuais dos animais são cíclicas, variando ao longo do tempo. Vários neurônios na área pré-óptica medial de macacos rhesus machos aumentam muito sua atividade durante fases específicas do comportamento sexual, incluindo a excitação e a cópula.

\section{O cérebro é um órgão sexualmente dimórfico?}

Uma das melhores evidências de que o cérebro é um órgão sexualmente dimórfico vem de trabalhos experimentais de Gorski, realizados em 1963, que mostravam alterações do comportamento sexual em ratas expostas à testosterona intra-útero (13). Suas primeiras observações mostravam que a castração de ratos em período neonatal produzia um macho que exibia comportamento feminino (postura lordótica). Por outro lado, a administração de testosterona a fềmeas aumentava a incidência de comportamento masculino. A partir desses achados, Gorski passou a observar alterações no sistema nervoso central que poderiam estar correlacionadas a esses comportamentos, chegando ao achado de um grupo de neurônios localizados no hipotálamo, numa área acima do quiasma óptico. Este núcleo foi chamado de "núcleo sexualmente dimórfico, situado na área pré-óptica (SDN-POA)", também conhecido como "núcleo intersticial do hipotálamo anterior”. O volume desse núcleo é quatro a cinco vezes maior em machos comparados a fêmeas. Estímulo funcional dessa área, com eletrodos implantados, aumentava a agressividade sexual masculina, ao passo que lesões ablativas não produziam alterações de comportamento em ratos sexualmente maduros, nem evitava a maturação sexual em ratos em período neonatal. Alguns estudos mostram que a ablação ou mesmo lesão na área pré-óptica interrompe o ciclo estral em fềmeas e, em machos, reduz a freqüência de cópulas.

Há vários grupos de neurônios chamados de núcleos intersticiais do hipotálamo anterior (INAH): o grupo chamado de INAH-1 parece ser o análogo humano do SDN-POA de ratos. Já os grupos INAH2 e INAH-3 são evidentemente maiores (cerca de duas a três vezes) em homens do que em mulheres.

$\mathrm{Na}$ estria terminalis, em sua porção que se cora em negro, encontramos o núcleo BNST (Bed Nucleus of the Stria Terminalis). Nas mulheres, o componente central do BNST e da área médio sagital da comissura anterior estão aumentados, o esplênio do corpo caloso é mais bulboso, o istmo do corpo caloso é maior e a massa intermédia está freqüentemente ausente quando comparados aos homens. As mulheres mostram um corpo caloso diminuído em relação aos homens, mas a comissura anterior é $12 \%$ maior em mulheres e em homens homossexuais do que em homens heterossexuais. No entanto, quando a massa intermédia está presente nas mulheres, ela mostra-se maior do que nos homens. Quando se estudam transexuais avaliando-se a quantidade de neurônios do BNST que expressam receptores de somatostatina, nota-se que, a despeito da orientação sexual, os homens apresentam o dobro de neurônios expressando somatostatina. Nos transexuais masculinos que optam pelo sexo feminino, o número é semelhante ao das mulheres, ao passo que nos transexuais femininos que optam pelo sexo masculino, o número é igual ao de homens. Estes achados apontam que, no caso dos transexuais, a diferenciação sexual cerebral pode caminhar em sentido oposto à diferenciação genital (14).

Até o momento, não temos uma noção clara do significado funcional de tais dimorfismos, mas sabemos que algumas dessas estruturas neurais, como o BNST, encontram-se na área de regulação do comportamento reprodutivo. Estudos realizados em pacientes que sofreram acidente vascular cerebral com lesão num único hemisfério mostraram que as funções do encéfalo feminino podem ser menos lateralizadas (menos dependentes da conexão inter-hemisférica) (13).

A conclusão que podemos tirar é que as estruturas dimórficas nos cérebros humanos são previsivelmente poucas, já que há grande semelhança no com- 
portamento sexual das mulheres e dos homens.

\section{Em que fase ocorre a diferenciação cerebral para masculina ou feminina?}

No atual estágio de entendimento, acreditamos que o "programa" inicial de desenvolvimento tanto do cérebro quanto do corpo é feminino. Ambos os sexos apresentam os primórdios (anlagen) para órgãos sexuais internos masculinos ou femininos e, ao menos em parte, a influência hormonal dirige a diferenciação: testosterona e seu metabólito reduzido, dihidrotestosterona, promovem a diferenciação de ductos internos e da genitália externa, respectivamente, para o sexo masculino, enquanto que, em ausência desses hormônios, expressa-se o "programa" inicial para sexo feminino.

Em animais de laboratório, a manipulação do ambiente hormonal durante o desenvolvimento perinatal altera permanentemente tanto a estrutura quanto a função do SNC: expor fêmeas a hormônio masculino viriliza componentes do SNC, enquanto a castração química ou cirúrgica do macho permite o desenvolvimento de um SNC do tipo feminino. Há evidências de que a aromatização local da testosterona a estrógeno é a responsável pela masculinização das estruturas cerebrais, ou seja, a testosterona atravessa a barreira hêmato-liquórica e, nas células cerebrais do núcleo sexualmente dimórfico, é convertida a estradiol, inibindo a apoptose dessas células. Já nas fềmeas, como o estrógeno circula perifericamente ligado à alfafeto-proteína, sua passagem ao SNC fica dificultada, não podendo exercer sua ação de inibição de apoptose em núcleos pré-ópticos (15).

Parece haver um "período crítico" para a diferenciação sexual, e este período é próprio para cada espécie. Dados experimentais em ratos apontam que o período crítico segue-se à diferenciação das células de Leydig e o início da produção de testosterona (16). No ser humano, a partir de 7-8 semanas de vida intra-uterina inicia-se a produção de testosterona e, de 14 a 18 semanas, as células de Leydig ocupam metade do volume do testículo fetal, involuindo progressivamente até o termo. O pico de produção de testosterona ocorre entre 14 e 16 semanas de vida intra-uterina, atingindo valores encontrados em homens adultos. Após o nascimento, a produção de testosterona é elevada nos 2 primeiros dias de vida, cai em seguida, voltando a subir com 2 semanas, mantendo-se elevada até 4-6 meses, sendo aos 2 o pico máximo de produção (figura 1) (5). Em analogia ao que ocorre em outras espécies, podemos supor que esses picos de produção de testosterona tenham significado especial no desenvolvimento sexual na

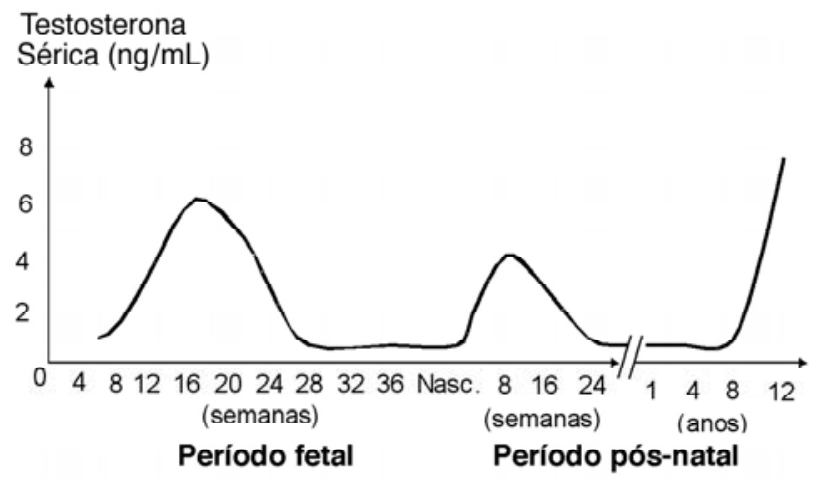

Fi gura 1. Evolução temporal da produção de testosterona desde a concepção até o pico puberal.

direção do sexo masculino.

Se o cérebro é um órgão sexual, quem comanda a diferenciação cerebral? Hormônios? Fatores genéticos? Fatores ambientais?

A primeira suspeita do que levaria o cérebro ao sexo masculino ou feminino estaria nos hormônios esteróides, diferencialmente produzidos em ambos os sexos: testosterona no sexo masculino, estradiol no feminino. Tem havido crescente evidência de que as flutuações nos níveis hormonais nos adultos estejam relacionadas a diferenças anatômicas das estruturas cerebrais em ambos os sexos. Como esses hormônios são esteróides, atuam no interior das células, tendo livre passagem através da membrana celular graças à sua solubilidade em lípides. O complexo hormônioreceptor citosólico dirige-se ao núcleo onde atua sobre o DNA induzindo ou reprimindo a transcrição de fatores que resultam num efeito final, específico para cada tecido. A idéia inicial é a de que a ausência de testosterona durante períodos críticos de desenvolvimento do sistema nervoso central levaria à formação de circuitos neurais diferentes no cérebro feminino, comparado ao masculino. Meyer-Bahlburg e cols. estudaram o efeito de um estrógeno sintético (Dietilstilbestrol-DES) que foi utilizado em gestações de risco até 1971, quando sua associação com adenocarcinoma de células claras da vagina e da cérvix uterina apressaram sua retirada do mercado. As comparações entre as meninas expostas ao DES pré-natal com suas irmãs indicavam que a exposição ao DES pode aumentar o desenvolvimento de um comportamento bissexual ou homossexual nessas mulheres. Três mecanismos são aventados: 1) ação do DES através da estimulação da produção de andrógenos; 2) efeitos tóxicos do DES sobre o cérebro em diferenciação; 3) uma ação do DES seme- 
lhante à do estradiol na diferenciação sexual do sistema nervoso central (17).

Talvez o modelo mais "simples" para a compreensão de como os hormônios esteróides orquestram a diferenciação de circuitos neurais esteja no núcleo espinhal bulbocavernoso em mamíferos (SNB), adjacente à base do pênis. Trata-se de uma pequena população de neurônios motores localizados na medula lombar que inerva a musculatura peniana em machos e é reduzido em tamanho nas fềmeas. Esses músculos têm um papel na ereção peniana e auxiliam na micção. Homens e mulheres possuem um músculo bulbocavernoso. Nas mulheres, ele circunda a abertura da vagina e serve para constringi-la levemente. $\mathrm{O}$ grupo de neurônios motores que controlam os músculos bulbocavernosos em humanos é chamado de núcleo de Onuf e está localizado na região sacral da medula espinhal. O núcleo de Onuf é moderadamente dimórfico (há mais neurônios motores em homens do que em mulheres) já que o músculo bulbocavernoso nos homens é maior em relação ao das mulheres. Nos ratos, as diferenças no número de neurônios do SNB ocorrem em período pós-natal. A partir de um número de neurônios igual em machos e fêmeas, ocorre degeneração dos neurônios motores desse núcleo, juntamente com a atrofia da musculatura peniana nas fêmeas. Já nos machos, os níveis androgênicos circulantes que ocorrem logo após o parto são responsáveis pela inibição da apoptose desses neurônios. Se as fềmeas forem tratadas precocemente com andrógenos, resgata-se a função dos neurônios motores do SNB (17).

Manfred Gahr, um neurocientista na Free Uni versity of Amsterdam na Holanda, criou seu próprio "pássaro confuso sexualmente" $(18,19)$. Antes do desenvolvimento gonadal, a região cerebral que comanda o comportamento sexual adulto foi alterada cirurgicamente. Se o conceito prevalente de que o cérebro sofre a ação dos hormônios gonadais fosse correto, o pássaro com o cérebro trocado não teria alterações, desde que as gônadas são preservadas. O que ocorreu, no entanto, é que as fềmeas que receberam o cérebro masculino comportavam-se como fêmeas mas os machos que receberam cérebros femininos não se comportavam como machos. Os seus testículos também não se desenvolveram normalmente, indicando que, pelo menos nesta espécie, um cérebro geneticamente masculino é requerido para completar o desenvolvimento gonadal (20).

Dewing e cols. estudaram, com a técnica de microarray, 12.000 genes ativos no cérebro em ratos machos e fềmeas, encontrando 51 com níveis diferentes de expressão em embriões, antes que as gônadas se tivessem formado. O gene que mostrava a maior expressão diferencial era o Xist, localizado no cromossomo $\mathrm{X}$, que se expressava 18,5 vezes mais em fêmeas. O peptídeo DEAD Box (Dby) e o fator de iniciação da tradução 2,Y (Eif2s3y), ambos no cromossomo Y, apresentavam a maior expressão diferencial em machos (10 e 8,8 vezes mais expressos nos machos, respectivamente). Isto sugere que, em mamíferos, os cérebros masculino e feminino iniciam as vias cerebrais de diferenciação sexual antes mesmo da formação gonadal (21). Tentando explorar a hipótese de que os genes atuam diretamente na diferenciação sexual cerebral e no comportamento sexual, de Vries e cols. compararam ratos $\mathrm{XX}$ e $\mathrm{XY}$ com ovários com ratos $\mathrm{XX}$ e $\mathrm{XY}$ com testículos. Apesar de a maioria dos fenótipos correlacionar-se com a presença de ovários ou testículos e, portanto, serem influenciados pelo ambiente hormonal, tanto os ratos machos e fêmeas com complemento cromossômico XY eram mais masculinos que os ratos XX na densidade de fibras imunorreativas a vasopressina no septo lateral, concluindo-se que os genes nos cromossomos sexuais contribuem diretamente com o desenvolvimento de diferenças sexuais no cérebro (22).

Na espécie humana, temos a situação das insensibilidades completas a andrógenos em que, devido a uma mutação do receptor androgênico, um indivíduo $46, \mathrm{XY}$, com testículos e produção adequada de testosterona e de dihidrotestosterona, não consegue virilizar sua genitália interna e externa, apresentando-se fenotipicamente como sexo feminino. Esses indivíduos apresentam uma adequada adaptação ao sexo feminino, sentindo-se como mulheres. Isto sugere um papel dos hormônios gonadais no dimorfismo cerebral humano, mediado por receptor androgênico, apesar de não haver, até o momento, estudo nos cérebros de tais pacientes $(7,13,23)$.

Mesmo sem dimorfismos sexuais nítidos, os circuitos neuronais mostram-se diferentes, justificando diferenças nos comportamentos masculino e feminino. Os hormônios sexuais determinam a identidade sexual do sistema nervoso durante o desenvolvimento inicial. A diferenciação sexual do sistema nervoso depende dos andrógenos produzidos pelos testículos desencadeando a "masculinização" do sistema nervoso central ao regular a expressão de uma variedade de genes relacionados ao sexo. Na ausência dos andrógenos, o sistema nervoso em desenvolvimento passa a ter diferentes características. Parece também haver uma discreta "feminização", o que significa que o cérebro das fềmeas não é simplesmente um sistema que deixou de sofrer a ação dos andrógenos.

Os esteróides podem influenciar os neurônios 
de duas formas gerais: 1) eles podem atuar rapidamente para alterar a excitabilidade da membrana, a sensibilidade aos neurotransmissores ou mesmo a liberação dos mesmos. Os esteróides fazem isso, em geral, ao se ligarem diretamente e por modularem as funções de várias enzimas, canais e receptores. Certos metabólitos da progesterona ligam-se ao receptor GABAérgico do tipo A e potencializam a quantidade de corrente de cloreto ativada pelo GABA. São efeitos muito parecidos aos ocasionados pelo uso de sedativos benzodiazepínicos e barbitúricos. 2) Os esteróides podem se difundir através da membrana e se ligar a tipos específicos de receptores para esteróides no citoplasma e no núcleo. Os receptores podem tanto inibir como promover a transcrição gênica específica para cada tipo de hormônio sexual (24).

Estudos em roedores mostram que a testosterona não possui efeito "masculinizante" no sistema nervoso central, sendo rapidamente transformada $\mathrm{em}$ estradiol pela ação da aromatase, e esse estradiol possui efeito "virilizante" no desenvolvimento do sistema nervoso dos machos. Uma vez que o pico estrogênico não ocorra, na presença das gônadas femininas, o cérebro das fêmeas escapam da transformação observada nos machos e, além disso, a ligação do estrógeno a alfa-feto-proteína dificulta sua passagem ao SNC (15).

Uma vez que hormônios, e não cromossomos, determinam diretamente as características sexuais do sistema nervoso, é possível existirem animais genotipicamente femininos com encéfalos masculinos e genotipicamente masculinos com encéfalos femininos. O tratamento com testosterona no início do desenvolvimento de alguma forma afeta a plenitude do comportamento feminino a longo prazo, o que pode ser bem observado em indivíduos com hiperplasia adrenal congênita que mostram, ao longo do desenvolvimento, um comportamento mais agressivo por parte das mulheres $(7,25)$.

Pesquisadores da universidade de Rockefeller descrevem um efeito fascinante dos esteróides: eles contaram as ramificações dendríticas nos neurônios do hipocampo de ratas e descobriram que o número de ramificações mudava intensamente durante o ciclo estral de cinco dias. A densidade de ramificações e os níveis de estradiol aumentavam paralelamente. Nos animais em que a produção própria de estradiol era mantida baixa, a injeção deste hormônio causava aumento do número de ramificações. Tendo em vista que as ramificações dendríticas são locais de sinapse no sistema nervoso, esses dados nos sugerem uma possível explicação para o fato de que a excitabilidade hipocampal também pareça acompanhar o ciclo estral.
O hipocampo de animais estudados experimentalmente pode ser mais facilmente superexcitado, isto é, desempenhar atividade epileptiforme, quando os níveis de estrógeno aumentam. Woolley e McEwen demonstram que é verdadeiramente o estradiol que desencadeia um aumento no número de ramificações dendríticas e que, à medida que os neurônios hipocampais desenvolvem mais ramificações, eles também passam a ter mais sinapses excitatórias. Mais ainda, as novas ramificações parecem ter mais receptores n-metil d-aspartato (NMDA) para o glutamato. Isto pode explicar, também, porque o estradiol aumenta a plasticidade sináptica de longo prazo no hipocampo. Estudos recentes mostram que a ação do estrógeno no hipocampo serve para diminuir a inibição sináptica. Os receptores para estradiol no hipocampo estão principalmente em interneurônios inibitórios, os quais, paradoxalmente, não são as células que desenvolvem mais ramificações. Contudo, o estradiol faz com que as células inibitórias produzam menos GABA, tornando sua inibição menos eficiente. Mulheres com atividade epileptiforme relatam que a freqüência e a gravidade de suas crises variam com os ciclos menstruais. Em geral, uma baixa quantidade de progesterona pode contribuir para a susceptibilidade às crises. Sendo o hipocampo uma estrutura extremamente relevante na habilidade de navegação e memória espacial, Woolley notou que o pico do número de ramificações dendríticas hipocampais coincide com o pico de fertilidade no rato. Durante esse período, as fêmeas procuram ativamente os parceiros, o que pode requerer uma maior habilidade para localização espacial que advém de um hipocampo mais excitável e repleto de receptores do tipo NMDA $(26,27)$.

\section{Quais as implicações práticas do con- hecimento do dimorfismo sexual cere- bral?}

Estudos recentes dos INAH sugerem que haja diferenças entre os cérebros de homo e heterossexuais que poderiam estar relacionadas com a orientação sexual. LeVay mostra diferenças estruturais no hipotálamo de homossexuais quando comparados aos heterossexuais, confirmando os dados de Laura Allen, da UCLA, de que o INAH-3 é cerca de duas vezes maior em homens do que em mulheres. Avaliando o cérebro de homossexuais, observa-se também uma acentuada diminuição da região INAH-3 em homens homossexuais, com tamanho comparável ao de mulheres heterossexuais. Apesar dessa diferença anatômica e conseqüentemente fisiológica, é difícil avaliarmos o complexo comportamento sexual e o correlacionarmos 
com essa alteração. A lesão do núcleo homólogo ao INAH-3 em ratos pouco interfere no comportamento sexual $(28)$.

Questões de lateralidade também têm sido avaliadas comparando-se homo e heterossexuais. Diferentes padrões de assimetria funcional cerebral são observados em homossexuais masculinos ou femininos, comparados a heterossexuais (29).

Dan Hamer e cols. acreditam haver um gene correlacionado com o dimorfismo sexual cerebral. Seu trabalho mostra uma maior probabilidade de um homem heterossexual vir a ser homossexual se houver na família algum indivíduo homossexual. Essa maior probabilidade estava mais diretamente relacionada a indivíduos homossexuais por parte materna do que paterna. Esse achado sugeriu que poderia haver alguma relação entre o cromossomo $\mathrm{X}$ e a orientação sexual. No estudo de Hamer e Bocklandt, o DNA do cromossomo $\mathrm{X}$ foi analisado em 40 pares de irmãos, não gêmeos, que fossem ambos homossexuais. Como sabemos que qualquer segmento específico de DNA, paterno ou materno, seria o mesmo para os dois irmãos somente $\mathbf{5 0 \%}$ das vezes, passou-se a verificar se essa proporção era mantida nesses irmãos estudados. Constatou-se que isso era verdade para a maior parte dos segmentos de DNA, exceto para uma porção na extremidade do cromossomo $\mathrm{X}$ que era muito mais provável de ser a mesma em irmãos homossexuais. A implicação para isso era de que essa parte do DNA, localizada na porção terminal braço longo do cromossomo X (Xq28), poderia codificar proteínas que de alguma forma fariam os encéfalos mais propensos a "funcionar" de uma forma homossexual (30).

Muitas questões têm sido levantadas com relação a crianças com anomalias da diferenciação sexual, que nascem com graus variados de ambigüidade genital. Esses casos têm sido encarados como verdadeiras "emergências médicas" e procura-se chegar a um diagnóstico etiológico precocemente, para que se possa atribuir um sexo de criação a estas crianças. Se em algumas situações as opções são claras, como por exemplo, nas meninas virilizadas por hiperplasia congênita de supra renais, onde a opção é pelo sexo feminino (são crianças com cariótipo 46,XX, estruturas internas e gônadas femininas, com potencial de fertilidade), em outras situações temos grandes dúvidas quanto à atribuição do gênero. É o caso, por exemplo, das insensibilidades androgênicas onde tenha ocorrido um pequeno grau de virilização da genitália externa, denotando uma grande resistência do receptor androgênico. Nesses casos, questiona-se se o uso de testosterona exógena será capaz de vencer o bloqueio do receptor a ponto de permitir uma adequada função no sexo masculino. Mais desconfortável é a situação em que ocorre uma deficiência de $5 \alpha$-redutase tipo 2 , em que a testosterona não é convertida a dihidrotestosterona, o hormônio responsável pela virlização da genitália externa. Esses pacientes, mesmo quando criados no sexo feminino, tendem a assumir o papel masculino na época da adolescência, mostrando que havia uma "marca" hipotalâmica já previamente estabelecida para o sexo masculino. As dúvidas chegam a tal ponto que há autores preconizando que se deixe a criança sem ter seu sexo definido, e se aguarde que ela própria, mais tarde, decida qual seu sexo. Convenhamos que é uma conduta complicada, levando-se em conta que essas crianças serão obrigadas a viver em uma sociedade em que a definição sexual já deve estar estabelecida cedo. Em alguns países como a República Dominicana, Nova Guiné, onde há alta incidência de deficiência de $5 \alpha$-redutase tipo 2 , aceita-se um "terceiro sexo", temporário, e essas crianças são mantidas nesse estágio de espera até que, na puberdade, ocorra a definição para o sexo masculino. Mesmo assim, as crianças passam por grande sofrimento em vista de serem proibidas de participarem de algumas atividades próprias do sexo masculino.

Se dispusermos de métodos que avaliem a característica cerebral de pacientes com anomalias da diferenciação sexual teremos aí um elemento importante para a atribuição do gênero e poderemos, talvez, evitar que mudanças de sexo em idades posteriores ocorram, com grande dose de sofrimento para os pacientes e para seus familiares. Em um estudo de 27 crianças com HCSR comparadas a 47 controles pareados por sexo e idade, foram avaliados por ressonância nuclear magnética os volumes do cérebro, ventrículos, lobo temporal, hipocampo e amígdala, demonstrando-se redução no tamanho da amígdala, estrutura com grande implicação funcional que merece exploração posterior (31). Este "mapeamento cerebral" em busca da característica sexual presente num determinado indivíduo merece ser perseguido e novos métodos de imagem devem ser desenvolvidos para tentarmos a caracterização do padrão anatômico e funcional do cérebro como definidor do sexo de criação do indivíduo.

\section{CONCLUSÕES}

Um longo caminho está por ser percorrido para que se desvendem os mistérios da caracterização sexual do cérebro humano. $\mathrm{O}$ conhecimento de estruturas específicas de cada sexo tem mostrado, ao menos em 
animais de experimentação, que o dimorfismo sexual do cérebro existe e tem sua contrapartida na espécie humana. A possibilidade de identificarmos essa marca cerebral do sexo em muito pode nos auxiliar na difícil tarefa de atribuição do sexo de criação em pacientes com anomalias da diferenciação sexual. Ainda nos dias de hoje, o desenvolvimento psicossexual, a atribuição de gênero e o tratamento cirúrgico em pacientes com anomalias da diferenciação sexual continuam tópicos controversos na literatura médica (15). Se há um comprometimento das estruturas cerebrais para um determinado sexo e se tivermos como avaliá-lo, teremos em mãos uma eficiente e poderosa arma no auxílio das decisões sobre o sexo de criação desses pacientes, talvez acarretando menos situações de inadequação sexual na vida adulta.

\section{REFERÊNCIAS}

1. Page DC, Mosher R, Simpson EM, Fisher EMC, Mardon G, Polack J, et al. The sex-determining region of the human $Y$ chromosome encodes a finger protein. Cell $1987 ; 51: 1091-104$.

2. Damiani D, Billerbeck AEC, Goldberg ACK, Setian N, Fellous M, Kalil J. Investigation of the ZFY gene in XX true hermaphroditism and Swyer syndrome. Hum Genet $1990 ; 85: 85-8$.

3. Sinclair AH, Berta P, Palmer MS, Hawkins JR, Griffiths BL, Smith MJ, et al. A gene from the human sex-determining region encodes a protein with homology to a conserved DNA-binding motif. $\mathrm{N}$ ature 199 0;346:240-4.

4. MacLaughln DT, Donahoe PK. Mechanisms of disease: sex determination and differentiation. $\mathbf{N}$ Engl J Med $2004 ; 350: 367-78$.

5. Damiani D. Anomalias da Diferenciação Sexual. In: Setian $\mathrm{N}$, editora. Endocrinologia Pediátrica - Aspectos físicos e metabólicos do recém-nascido ao adoles cente. São Paulo:Sarvier; 2 002.p. 425-72.

6. Mendonça BB, Inácio M, Costa EM, Arnhold IJ, Silva FA, Nicolau W, et al. Male pseudohermaphroditism due to steroid 5alpha-reductase 2 deficiency. Diagnosis, psychological evaluation, and management. Medicine (Baltimore) 1 996;7 5:64-76.

7. Zucker KJ. Intersexuality and gender identity differentiation. Ann Rev Sex Res 1999;10:1-69.

8. Phornphutkul C, Fausto-Sterling A, Fruppuso PA. Gender self-reassignment in an $\mathrm{XY}$ adolescent female born with ambiguous genitalia. Pediatrics 2 000;1 06:135-7.

9. Ocal G, Adiyaman P, Berberoglu M, Cetinkaya E, Akar N, Uysal A, et al. Mutations of the 5alpha-steroid reductase type 2 gene in six Turkish patients from unrelated families and a large pedigree of an isolated Turkish village. $J$ Pediatr Endocrinol Met ab 2002;15:411-21.

10. Arnold AP, Xu J, Grisham W, Chen X, Kim Y, Itoh Y. Minireview: Sex chromosomes and brain sexual differen- tiation. End ocrinology 200 4;145:1057-62.

11.Dennis C. The most important sexual organ. Nature 2004;427:390-3.

12. Kirn J, Lombroso PJ. Development of the cerebral cortex: XI. Sexual dimorphism in the brain. J Am Acad Child Adolesc Psychiatry 19 98;37:1228-30.

13. Gorski RA. Development of the cerebral cortex: XV. Sexual differentiation of the central nervous system. J A m Acad Child Adolesc Psychiatry 199 9;38:344-6.

14. Kruijver FPM, Zhou J, Pool CW, Hofman MA, Gooren LJG, Swaab DF. Male-to-female transsexuals have female neuron numbers in a limbic nucleus. J Clin Endocrinol Metab 2000;85:2034-41.

15. Hrabovszky Z, Hutson JM. Androgen imprinting of the brain in animal models and humans with intersex disorders: review and recommendations. J Urol 2002;168:2142-8.

16. Weisz J, Ward IL. Plasma testosterone and progesterone titers of pregnant rats, their male and female fetuses and neonatal offspring. Endocrinology $1980 ; 106: 306-16$.

17. Meyer-Bahlburg HFL, Ehrhardt AA, Rosen LR, Gruen RS. Prenatal estrogens and the development of homosexual orientation. Dev Ps ychol 1 995;31:12-21.

18. Gahr M, Leitner S, Fusani L, Rybak F. What is the adaptive role of neurogenesis in adult birds? Prog B rain Res 2003;138:233-54.

19. Gahr M. Male Japanese quails with female brains do not show male sexual behaviors. Proc $\mathrm{N}$ atl Acad $\mathrm{S} \mathrm{ci}$ USA 2003;100:7959-64.

20. Kirn JR, de Voogd TJ. Genesis and death of vocal control neurons during sexual differentiation in the zebra finch. J Neurosci 1 989;9:3176-87.

21. Dewing $P$, Shi T, Horvath S, Vilain E. Sexually dimorphic gene expression in mouse brain precedes gonadal differentiation. Mol Brain Res 2003;1 18:82-90.

22. De Vries GJ, Rissman EF, Simerly RB, Yang L, Scordalakes EM, Auger CJ, et al. A model system for study of sex chromosome effects on sexually dimorphic neural and behavioral traits. J Neurosci 2002;22:9005-14.

23. Wilson JD. Androgens, androgen receptors, and male gender role behavior. Horm B ehav 2001 ;40:358-66.

24. Moshe SL. Sex and the substantia nigra: administration, teaching, patient care, and research. J Clin Neurophysiol 199 7;14:484-94.

25. Zucker KJ, Bradley SJ, Oliver G, Blake J, Fleming S, Hood J. Self-reported sexual arousability in women with congenital adrenal hyperplasia. J S ex Mar Ther 2003 , in press.

26. Woolley CS, McEwen BS. Estradiol regulates hippocampal dendritic spine density via a methyl-D-aspartate receptor-dependent mechanism. J Neurosci 1 9 94;14: 7680-7.

27. Woolley CS, Weiland NG, McEwen BS, Schwartzkroin PA. Estradiol increases the sensitivity of hippocampal CA1

Arq Bras Endocrinol Metab vol 49 n 1 Fevereiro 2005 
pyramidal cells to NMDA receptor-mediated synaptic input: correlation with dendritic spine density. J Neurosci 1 99 7;17:1848-54.

28. LeVay S. A difference in hypothalamic structure between heterosexual and homosexual men. Science 199 1;253:1034-7.

29. McCormick CM, Witelson SF. Functional cerebral asymmetry and sexual orientation in men and women. Be hav Neurosci 1 994;108:525-31.
30. Hamer DH, Bocklandt S. Beyond hormones: a novel hypothesis for the biological basis of male sexual orientation. J Endocrinol Inv est 2003;26(Suppl):8-12.

31. Merke DP, Fields JD, Keil MF, Vaituzis AC, Chrousos GP, Giedd JN. Children with classic congenital adrenal hyperplasia have decreased amygdala volume: potential prenatal and postnatal hormonal effects. J Clin Endocrinol Metab 200 3;88:1760-5.

\section{Endereço para correspondência:}

Durval Damiani

Rua Bela Cintra 2117, apto 9

01415-002 São Paulo, SP

E-mail: durvald@iconet.com.br 